\title{
Diversity in the erg27 Gene of Botrytis cinerea Field Isolates from Strawberry Defines Different Levels of Resistance to the Hydroxyanilide Fenhexamid
}

\author{
Achour Amiri and Natalia A. Peres, University of Florida, Gulf Coast Research and Education Center, Wimauma 33598
}

\begin{abstract}
Amiri, A., and Peres, N. A. 2014. Diversity in the erg27 gene of Botrytis cinerea field isolates from strawberry defines different levels of resistance to the hydroxyanilide fenhexamid. Plant Dis. 98:1131-1137.

The hydroxyanilide (Hyd) fenhexamid has played a major role in gray mold management in Florida strawberry fields since 2000. Recent monitoring of the sensitivity of Botrytis cinerea to fenhexamid indicated that resistance has emerged. In this study, mutations in the target gene erg27 encoding the 3-keto reductase enzyme were investigated and the shift in fenhexamid sensitivity over time was evaluated in 630 isolates collected between 2005 and 2013 from locations sprayed with different spray programs. Overall, 227, 155, 48, and 200 isolates were sensitive $\left(\mathrm{Hyd}^{\mathrm{S}}\right)$, had reduced sensitivity (HydR2), or were moderately $\left(\mathrm{HydR}^{-}\right)$and highly $\left(\mathrm{HydR}^{+}\right)$resistant, respectively. Analysis of complete sequences of the erg27 gene from 70 isolates revealed seven and five mutations and one deletion in the HydR3- and HydR $3^{+}$isolates, respectively, at eight and five different codons, respectively. In addition to the three mutations (F412S, -I, and -V) reported previously at codon 412, two new mutations from glycine to arginine at codon 170

(G170R, two isolates) and from alanine to glycine at codon 210 (A210G, eight isolates) were detected for the first time in $\mathrm{HydR}^{+}$ isolates from Florida. These isolates were not controlled on detached fruit sprayed with the recommended field rate of fenhexamid, whereas all $\mathrm{Hyd}^{\mathrm{S}}$, HydR2, and HydR3- isolates were controlled on detached fruit. Overall, there was no clear correlation between the spray frequency of fenhexamid and the frequency of resistant phenotypes. This study provides an overview of the current distribution of erg27 genotypes in Florida and will serve as a baseline for future studies on shifts in population diversity and resistance. The frequency of fenhexamidresistant populations has increased progressively in different strawberry fields but has not reached a plateau yet, indicating that the effective life of fenhexamid could be extended if appropriate rotation and management strategies are implemented. Sensitivity to other sterol biosynthesis inhibitors is discussed.
\end{abstract}

Gray mold, caused by Botrytis cinerea, is one of the most destructive fungal species of strawberry and more than 200 other plant species (37). On strawberry, primary infections most often occur on senescent leaves and remain latent until weather conditions become favorable for sporulation, then spread to other parts of the plant. The fungus attacks nearly all parts of strawberry plant but can be particularly destructive to fruit, causing gray mold when temperatures around $20^{\circ} \mathrm{C}$ and high humidity persist for several days in the field. In Florida, weekly applications of numerous single-site fungicides in addition to captan and thiram, two multisite fungicides, are recommended for gray mold management throughout the season. However, the single-site fungicides have been recommended particularly during bloom and peak fruit production, which occurs mainly in mid-November and early February in Florida (22). The risk for resistance development is higher for the single-site fungicides, especially for a high-risk pathogen such as $B$. cinerea, for which resistance has been reported to almost all registered fungicides $(2,5,23,25,26,31,36)$.

Three different groups of sterol biosynthesis inhibitors (SBIs) are used as agricultural fungicides: those targeting the sterol $14 \alpha-$ demethylases (DMIs) such as prochloraz, tebuconazole, and propiconazole; the sterol $\Delta^{14}$ reductase and the $\Delta^{8}-\Delta^{7}$ isomerase (amines) such as fenpropimorph and dodemorph; and those targeting the $\mathrm{C}-4$ demethylase enzyme (hydroxyanilides [Hyds]) such as fenhexamid. The DMIs and the amines are known to have a wide spectrum of action, whereas the Hyds are active only against $B$.

Corresponding author: A. Amiri, E-mail: aamiri@ufl.edu

* The $\boldsymbol{e}$-Xtra logo stands for "electronic extra" and indicates that Figure 2 appears in color online.

Accepted for publication 11 February 2014.

http://dx.doi.org/10.1094/PDIS-11-13-1171-RE

(C) 2014 The American Phytopathological Society cinerea, Sclerotinia spp., and Monilinia spp. (32). Fenhexamid, a unique fungicide from the Hyd group, has been part of the overall gray mold management program on strawberry in Florida since 2000. It is recommended for up to four applications per season either as a single product (Elevate 50WDG) or mixed with captan (Captevate 68WDG) (35). Fenhexamid has a greater activity against mycelial growth than against conidial germination in vitro $(20,25)$. In vivo, fenhexamid is a protectant, locally systemic fungicide proven to reduce colonization of flowers by $B$. cinerea and to enhance control of gray mold in strawberry $(22,29)$.

Fenhexamid targets 3-keto reductase (3-KR), one of the three microsomal enzymes involved in the inhibition of the C4-demethylation complex $(10,21)$, and is classified as low to medium risk for resistance development (17). Resistance to fenhexamid in $B$. cinerea has been reported in vineyards in Europe and in the Americas $(1,6,12,14,23,33,36)$, in different vegetable crops in Greece (31), and, recently, in strawberry $(2,19)$ and heuchera $(30)$ in the United states. Different resistant phenotypes (i.e. HydR1, HydR2, $\mathrm{HydR}^{-}$, and $\mathrm{HydR}^{+}$) have been identified in B. cinerea from French and Chilean vineyards $(13,14)$. HydR1, which confers natural resistance to the Hyds, was described in $B$. pseudocinerea from France, whereas HydR 2 includes $B$. cinerea isolates with a moderate level of resistance. HydR3- $3^{-}$phenotypes have been described in Chilean, French, and German vineyards and exhibited moderate to high level of resistance to fenhexamid which was linked to several mutations in the erg27 gene (i.e., L195F, L400F, and L400S; 13,14). HydR $3^{+}$isolates have a high level of resistance to fenhexamid, which was commonly linked to a point mutation at codon 412 in the $\operatorname{erg} 27$ gene (14). These mutations were recently suggested to be deleterious to mutants carrying them compared with the wildtype (WT) isolates under laboratory conditions (8). However, the fenhexamid-resistant mutants were able to grow, sporulate, and produce sclerotia on artificial media at temperatures $\left(20\right.$ to $\left.26^{\circ} \mathrm{C}\right)$ similar to those usually encountered in Florida during and after the strawberry season (8). The effect of such mutations on the survival and spread of fenhexamid-resistant isolates in the field and their effect on management strategies is unknown. 
A recent study conducted in some strawberry fields in Florida revealed an emerging resistance to fenhexamid, with some disparity in resistance frequencies across locations (2). Resistance to fenhexamid was not as widespread as it was for the succinate dehydrogenase inhibitor (SDHI), the quinone outside inhibitor (QoI), or the anilinopyrimidine (AP) fungicides (2). Moreover, two different phenotypes linked with sensitivity to fenhexamid were observed, including isolates with moderate resistance $\left(\mathrm{Hyd}^{\mathrm{MR}},>1\right.$ effective concentration inhibiting $50 \%$ growth $\left.\left(\mathrm{EC}_{50}\right)<10 \mu \mathrm{g} / \mathrm{ml}\right)$ and others with high resistance $\left(\mathrm{Hyd}^{\mathrm{HR}}, \mathrm{EC}_{50} \geq 10 \mu \mathrm{g} / \mathrm{ml}\right)$. To better understand the factors affecting the development of resistance to the Hyds, we initiated this study to (i) characterize the molecular mechanism involved in resistance to fenhexamid in $B$. cinerea field isolates with different sensitivity phenotypes, (ii) evaluate the effect of spray frequency on the distribution and the frequency of fenhexamid-resistant phenotypes, and (iii) evaluate the in vitro and in vivo efficacy of other sterol inhibitor fungicides (SBIs) that are not currently registered for the control of $B$. cinerea in strawberry.

\section{Materials and Methods}

Fungal isolates. In all, 630 isolates of $B$. cinerea collected between 2005 and 2013 from 18 strawberry fields in Florida were used in this study. Isolates were recovered from 14 fields in Hillsborough County, where the majority of strawberry fruit are grown in Florida, from 1 field in Citrus County and 3 fields in Polk County. These fields were sprayed at least once a year with fenhexamid or fenhexamid + captan (Elevate or Captevate; Arysta LifeScience) since these products were registered in Florida in 2001. In total, 37 isolates were collected between 2005 and 2010 whereas 60, 300, and 233 isolates were collected in 2011, 2012, and 2013, respectively. Symptomatic fruit and asymptomatic flowers (in 2013) were collected in February and March after most fungicide treatments were made. Asymptomatic flowers were surface sterilized for $2 \mathrm{~min}$ in $0.05 \%$ sodium hypochlorite, rinsed twice in sterile water, incubated in humid boxes at $22^{\circ} \mathrm{C}$, and checked for $\mathrm{Bo}$ trytis sp. sporulation after 5 to 7 days. Conidia from symptomatic fruit and flowers were transferred to general isolation medium (19.5 g of potato dextrose agar and $9.5 \mathrm{~g}$ of agar/litter) amended with ampicillin (250 mg/liter) and streptomycin (100 mg/liter) and plates were incubated for $48 \mathrm{~h}$. Afterward, a plug was taken from the edge of a growing colony, transferred to malt yeast extract agar (MYA), and incubated until profuse sporulation was observed. Isolates were single spored and stored in $20 \%$ glycerol at $-80^{\circ} \mathrm{C}$. One isolate only was obtained per fruit or flower. Mycelium freshly grown from stock cultures was used for each new experiment. Four commercial strawberry fields (AS, FY, PC, and SS), located in the Plant City and Dover area, were surveyed regularly

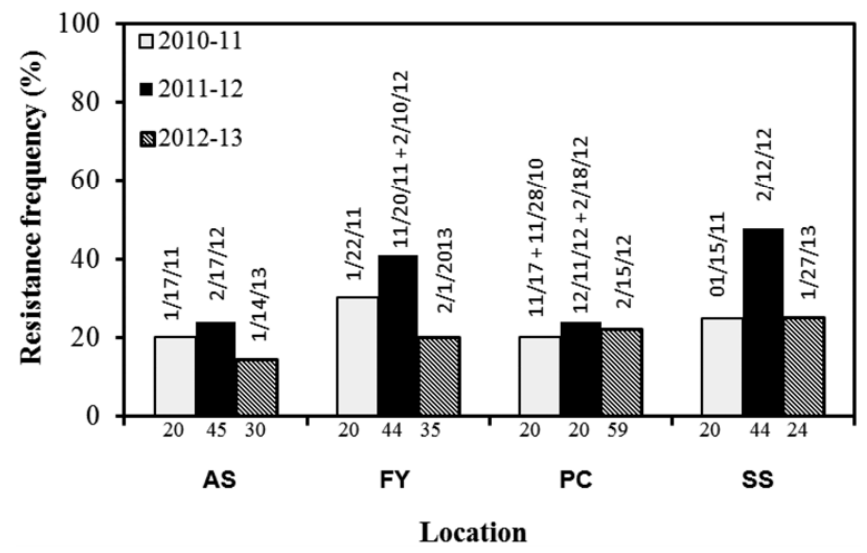

Fig. 1. Resistance frequency to fenhexamid in Botrytis cinerea field populations from four strawberry locations (AS, FY, PC, and SS) sprayed differentially between 2010 and 2013. Dates of sprays for each location and season are shown above each bar. Numbers below bars indicate the number of $B$. cinerea isolates tested for each location and year. between 2010 and 2013 to evaluate the effect of fenhexamid spray frequency on resistance frequency. The spray records were obtained from growers for each location (Fig. 1).

Evaluation of sensitivity of $B$. cinerea to fenhexamid and other SBIs. The Hyd fenhexamid (Elevate WDG; Arysta LifeScience); the imidazole prochloraz (Sportak; Bayer CropScience); the triazoles fenbuconazole (Indar; Dow AgroSciences), metconazole (Quash; Valent), and tetraconazole (Mettle; Isagro); the mopholine-fenpropimorph (technical grade; Sigma-Aldrich); and the spiroketal-amine spiroxamine (technical grade, Sigma-Aldrich) were tested in this study. Sensitivity was evaluated after $48 \mathrm{~h}$ of incubation on potato dextrose agar (PDA) based on mycelial growth inhibition assays at $22^{\circ} \mathrm{C}$ under continuous light using the spiral gradient dilution (SGD) method developed by Förster et al. (15) and modified by Amiri et al. (2). Stock solutions of 16.8, 9.1, $8.7,8.5,9.1,8.4$, and $8.3 \mathrm{mg} / \mathrm{ml}$ of fenhexamid, prochloraz fenbuconazole, metconazole, tetraconazole, fenpropimorph, and spiroxamine, respectively, were prepared in sterile distilled water or methanol for technical grades and stored at $4^{\circ} \mathrm{C}$. These concentrations allowed radial concentration ranges from the perimeter to the center of the plate between 0.75 and $>123.3,0.35$ and $>70.65,0.37$ and $>68.4,0.37$ and $67.41,0.35$ and $70.41,0.37$ and $>66.32$, and 0.37 and $>65.88 \mu \mathrm{g} / \mathrm{ml}$, respectively. Three plates were used for each isolate-fungicide combination and the test was conducted twice. Sensitivity to fenhexamid was evaluated using the SGD method in 337 isolates collected before 2013 and using a discriminatory dose of $10 \mu \mathrm{g} / \mathrm{ml}$ on PDA for the 233 isolates collected in 2013. Sensitivity to the other six SBIs was tested in 40 isolates using the SGD method.

DNA manipulations. In total, 170 isolates were grown on MYA for 7 to 10 days or until profuse sporulation was observed and genomic DNA was extracted from conidia using the FastDNA kit (MP Biomedicals) according to the manufacturer's protocol. All 170 isolates investigated molecularly in this study belong to the species B. cinerea sensu stricto based on a marker in the hch gene (16).

The primers erg27Beg (5'-TGGGATTACCACCATGGGAGA CAAGTG- $\left.3^{\prime}\right)$ and erg27End (5'-CAATGGTTCCGCATTTCT TTGCCTCC-3') (14) were used to amplify approximately 1,000 bp fragment of the erg27 gene from 70 isolates showing different sensitivity levels to fenhexamid in vitro. Polymerase chain reactions (PCRs) were performed in 50- $\mu$ l mixtures containing $2 \mu \mathrm{l}$ of $10 \times$ buffer (New England Biolabs), $1.5 \mathrm{mM} \mathrm{MgCl}_{2}, 2 \mathrm{mM}$ dNTPs (Promega Corp.), $0.2 \mu \mathrm{M}$ each primer, and $0.5 \mathrm{U}$ of Taq polymerase (New England Biolabs). PCRs were performed in a PTC-200 thermal cycler (MJ Research) using the following parameters: an initial denaturation at $95^{\circ} \mathrm{C}$ for $3 \mathrm{~min} ; 35$ cycles of $95^{\circ} \mathrm{C}$ for $15 \mathrm{~s}$, $68^{\circ} \mathrm{C}$ for $30 \mathrm{~s}$, and $68^{\circ} \mathrm{C}$ for $1 \mathrm{~min}$; and a final extension at $68^{\circ} \mathrm{C}$ for $2 \mathrm{~min}$. PCR products were sequenced and aligned as described previously (3).

Five point mutations resulting in changes in amino acid sequence were detected in the highly resistant $\left(\mathrm{HydR} 3^{+}\right)$isolates at codon 170 from glycine to arginine (G170R), at codon 210 from alanine to glycine (A210G), and at codon 412 from phenylalanine to either a serine $(\mathrm{F} 412 \mathrm{~S})$, an isoleucine $(\mathrm{F} 412 \mathrm{I})$, or a valine (F412V) in the erg27 gene. An allele-specific primer set Erg27-F1 (5'-TGAATCTCCGGAAGAACCAC-3') and F412S-R (5'-CCC ATCCATCTTACAAGGTAGG-3') was designed to detect the F412S mutation. PCRs were conducted as detailed above in $25-\mu \mathrm{l}$ volumes using an initial denaturation at $95^{\circ} \mathrm{C}$ for $3 \mathrm{~min} ; 35$ cycles of $94^{\circ} \mathrm{C}$ for $30 \mathrm{~s}, 67^{\circ} \mathrm{C}$ for $50 \mathrm{~s}$, and $72^{\circ} \mathrm{C}$ for $1 \mathrm{~min}$; and a final extension at $72^{\circ} \mathrm{C}$ for $5 \mathrm{~min}$. The analysis of the $\operatorname{erg} 27$ sequences from $\mathrm{HydR}^{+}$isolates using the NEBcutter $\mathrm{V} 2$ revealed the presence of a unique $A c c \mathrm{I}$ (GT/MKAC) and BcII (TGATC/A) restriction site in the isolates carrying the F412V and F412I mutations, respectively. Therefore, these two mutations were detected using a PCR restriction fragment length polymorphism (RFLP) assay. Partial fragments ( $800 \mathrm{bp}$ ) of the erg27 gene were amplified from sensitive $\left(\mathrm{Hyd}^{\mathrm{S}}\right)$ and $\mathrm{HydR} 3^{+}$isolates using the primer pair Erg27-F1/F412S-R developed in this study as described for the $\mathrm{F} 412 \mathrm{~S}$, except that a temperature of $58^{\circ} \mathrm{C}$ for $50 \mathrm{~s}$ was used during 
the annealing step. To detect the F412V and F412I mutants, PCR products were digested with the enzymes AccI (Fermentas Inc.) and $B c$ II (Fermentas Inc.), respectively, as recommended by the manufacturer and separated on a $2 \%$ agarose gel.

Fruit tests. To assess the ability of the moderately resistant (HydR2) and HydR3 isolates to cause gray mold, 32 isolates from 13 different genotypes (at least 2 isolates/genotype) were grown on MYA for 7 to 10 days and spore suspensions at $10^{6}$ conidia/ml were prepared as explained previously (2). Blackberry fruit were used instead of strawberry to evaluate the sensitivity of isolates after previous tests showed no differences in evaluating sensitivity levels (2). Blackberry fruit were disinfected, stubbed, sprayed with fungicides, and inoculated as described by Amiri et al. (2). Eight fruit per isolate were sprayed with fenhexamid (Elevate) at the recommended field rate (RFR) of $1.8 \mathrm{~g} /$ liter and inoculated $24 \mathrm{~h}$ post spray. Control fruit were sprayed with sterile water. Gray mold incidence and sporulation were evaluated after 5 days of incubation at $22^{\circ} \mathrm{C}$. The test was repeated twice. Formulated prochloraz and metconazole were applied to fruit at RFR of 0.27 and $225 \mu \mathrm{g} / \mathrm{ml}$, respectively. Twelve isolates from different genotypes were tested and gray mold incidence was determined 3, 5, and 7 days post inoculation (dpi).

Data analysis. Data from in vitro sensitivity tests from repeated experiments were combined after homogeneity of variance between experiments was tested using Bartlett's test. Sensitivity was expressed as $\mathrm{EC}_{50}$ in micrograms per milliliter or as resistance factor computed by dividing the $\mathrm{EC}_{50}$ value for each isolate by the lowest $\mathrm{EC}_{50}$ value within the population for each fungicide, separately. Pearson coefficients were calculated to determine correlation between number of fungicide application and resistance frequencies. $\mathrm{EC}_{50}$ values and data from detached fruit assays were subjected to one-way analysis of variance and means were separated using Fisher's least significant difference test. All statistical analyses were performed using the SAS software (version 9.2; SAS Institute Inc.).

\section{Results}

Sensitivity to fenhexamid and other SBIs in vitro. None of the 37 isolates collected between 2005 and 2010 was resistant to fen- hexamid. In all, 35 had resistance factors (RFs) lower than 10 whereas 2 isolates were HydR2 ( $\mathrm{RF}=10$ to 20; Table 1$)$. The frequency of $\mathrm{Hyd}^{\mathrm{S}}$ isolates decreased from $94.6 \%$ prior to 2011 to 46.6 and $30 \%$ in 2011 and 2013, respectively. The frequency of HydR2 and HydR3 ${ }^{-}(\mathrm{RF}=20$ to 60) isolates increased over years and reached 30 and $10 \%$, respectively, in 2013. The frequency of HydR $^{+}(\mathrm{RF}=40$ to 2,200) stabilized around $30 \%$ even though a peak of $36 \%$ was observed in the 2011-12 season. The different Hyd phenotypes were found across all locations surveyed between 2011 and 2013 (data not shown).

The imidazole prochloraz and triazole metconazole were the most effective SBIs against all isolates $(n=40)$ tested in vitro regardless of their genotype, whereas tetraconazole was less effective (Table 2). Among the two amine fungicides tested, the morpholine fenpropimorph was highly effective in vitro compared with the spiroketal-amine spiroxamine, with $\mathrm{EC}_{50}$ values of 0.57 to 1.19 and 7.11 to $10.25 \mu \mathrm{g} / \mathrm{ml}$, respectively. Although not always significantly different, the mean $\mathrm{EC}_{50}$ values for all DMIs were slightly higher in the WT isolates compared with those carrying a mutation at codon 412 of the erg27 gene (Table 2). The F412S mutants were most sensitive to all DMIs whereas the F $412 \mathrm{~V}$ were less sensitive to fenpropimorph (Table 2).

Effect of number of fenhexamid applications on resistance frequency in strawberry fields. Results from resistance monitoring conducted for three seasons at four locations did not reveal a clear correlation between the number of fenhexamid sprays and selection for resistant populations. Resistance frequencies of $\mathrm{HydR}^{+}$isolates were the lowest (14 to $24 \%$ ) at the AS location, where fenhexamid was only sprayed once a year (Fig. 1). Resistance frequencies in the PC location remained close to $20 \%$ over the 3 years of evaluation, although fenhexamid was sprayed twice in the 2010-11 and 2011-12 seasons. The highest resistance frequencies were observed in the FY location (41\%) and in the SS location (47\%) in the 2011-12 season (Fig. 1).

Analysis of $\operatorname{erg} 27$ sequences from $\mathrm{Hyd}^{\mathrm{S}}$ and $\mathrm{HydR}$ isolates. The complete $\operatorname{erg} 27$ gene was amplified and sequenced in 70 isolates from different phenotypes. Sequence analyses revealed seven amino acid substitutions and one deletion in the $\operatorname{erg} 27$ gene of the HydR3- isolates (Table 3). The most frequent substitutions were

Table 1. Overall annual frequency of phenotypes sensitive or resistant to fenhexamid in Botrytis cinerea populations collected from strawberry commercial fields in Florida between 2005 and 2013

\begin{tabular}{l}
\hline \\
\cline { 2 - 5 }
\end{tabular}

Table 2. In vitro sensitivity of HydR $3^{+}$phenotypes of Botrytis cinerea to seven sterol biosynthesis inhibitors

\begin{tabular}{|c|c|c|c|c|c|c|c|}
\hline \multirow[b]{3}{*}{ erg27 Genotype } & \multicolumn{7}{|c|}{ Mean $\mathrm{EC}_{50}(\mu \mathrm{g} / \mathrm{ml})$ for sterol inhibitor fungicides ${ }^{\mathrm{Z}}$} \\
\hline & \multirow{2}{*}{$\frac{\text { Hydroxyanilide }}{\text { Fenhexamid }}$} & \multicolumn{4}{|c|}{ Sterol $14 \alpha$-demethylases } & \multicolumn{2}{|c|}{ Amines } \\
\hline & & Prochloraz & Fenbuconazole & Metconazole & Tetraconazole & Fenpropimorph & Spiroxamine \\
\hline$\overline{\mathrm{Hyd}^{\mathrm{S}}}$ & $0.49 \mathrm{~d}$ & $0.68 \mathrm{a}$ & $0.68 \mathrm{a}$ & $0.55 \mathrm{a}$ & $1.08 \mathrm{a}$ & $0.76 \mathrm{~b}$ & $8.42 \mathrm{a}$ \\
\hline A210G & $9.53 \mathrm{c}$ & $0.50 \mathrm{~b}$ & $0.58 \mathrm{ab}$ & $0.46 \mathrm{~b}$ & $0.68 \mathrm{ab}$ & $0.74 \mathrm{~b}$ & $8.81 \mathrm{a}$ \\
\hline F412I & $31.26 \mathrm{a}$ & $0.45 \mathrm{bc}$ & $0.53 \mathrm{~b}$ & $0.48 \mathrm{~b}$ & $0.69 \mathrm{ab}$ & $0.57 \mathrm{~b}$ & $7.11 \mathrm{a}$ \\
\hline $\mathrm{F} 412 \mathrm{~S}$ & $18.01 \mathrm{~b}$ & $0.28 \mathrm{c}$ & $0.37 \mathrm{c}$ & $0.32 \mathrm{c}$ & $0.49 \mathrm{c}$ & $0.92 \mathrm{~b}$ & $9.65 \mathrm{a}$ \\
\hline F412V & $15.31 \mathrm{bc}$ & $0.30 \mathrm{c}$ & $0.61 \mathrm{~b}$ & $0.37 \mathrm{c}$ & $0.78 \mathrm{ab}$ & $1.19 \mathrm{a}$ & $10.25 \mathrm{a}$ \\
\hline
\end{tabular}

${ }^{\mathrm{z}}$ Mean effective concentration inhibiting $50 \%$ growth $\left(\mathrm{EC}_{50}\right)$ value in micrograms per milliliter for each fungicide from eight isolates tested for each genotype. Data are the mean of 12 individual values across two experimental runs (three plates $\times$ two agar strips $\times$ two replications). Values within the same column followed by the same letter are not significantly different based on analysis of variance test and Fisher's least significant difference separations at $P$ $=0.05$. 
leucine to phenylalanine at codon 400 (L400F) and alanine to serine at codon 461 (A461S), found in 6 and 13 isolates, respectively. The substitutions of asparagine to threonine (N196T) and proline to serine (P250S) at codons 196 and 250, respectively, were detected in two isolates (13-53 and 13-69), simultaneously, whereas a deletion of proline at codon $298(\Delta \mathrm{P} 298)$ was detected in four isolates, among which two (13-53 and 13-69) had the N196T substitution (Table 3).

The entire population of B. cinerea collected in 2011 and 2012 was screened for the F412S, -I, and -V mutations using sequencing (70 isolates), AP-PCR, and PCR-RFLP assays. Three mutations were detected at codon 410 of the erg27 gene of the HydR $3^{+}$ isolates (Table 3). The F412S was more frequent (87 isolates), followed by the F412I and F412V found in 27 and 14 isolates, respectively (Table 3). Additionally, results from sequencing revealed two new mutations; that is, glycine to arginine at codon 170 (G170R) and alanine to glycine at codon 210 (A210G) in two and eight $\mathrm{HydR}^{+}{ }^{+}$isolates, respectively(Table 3). Two restrictions sites (HpyAV and $C V I K-1)$ were detected within or in the vicinity of the G170 and A210 codons, respectively, but the entire population has not yet been fully screened for these two mutations.

Pathogenicity of the HydR3 mutants and efficacy of other SBIs in vivo. All HydR $3^{-}$isolates were inhibited on PDA amended with fenhexamid at $1.0 \mu \mathrm{g} / \mathrm{ml}$ after 8 days of incubation at $22^{\circ} \mathrm{C}$ (Fig. 2). All HydR $3^{-}$isolates grew on concentrations up to $3.0 \mu \mathrm{g} / \mathrm{ml}$ after 14 days of incubation (data not shown). HydR3- isolates were also inhibited on detached fruit sprayed preventively with the recommended rate of fenhexamid, except $\mathrm{HydR}^{-}$isolate 12-38 (I232M) after 7 days of incubation (Table 2). Although the RFs of the G170R and A210G mutants were lower than those of isolates carrying a mutation at codon 412, these isolates were neither inhibited on PDA amended with fenhexamid at $10 \mu \mathrm{g} / \mathrm{ml}$ (Fig. 2) nor controlled by the RFR of fenhexamid on detached fruit (Table 2).

The high in vitro efficacy of prochloraz and metconazole translated into complete gray mold control on detached fruit after 3 days, regardless of the genotype (data not shown). Gray mold incidence varied from 0 to $50 \%$ for prochloroz and 0 to $100 \%$ for metconazole after 5 and 7 days of incubation at $22^{\circ} \mathrm{C}$ (Table 4).

\section{Discussion}

Since the advent of resistance to the SDHIs and QoIs in Florida, the Hyd fenhexamid has been a mainstay for gray mold management in strawberry fields, in addition to the phenylpyrroles and anilinopyrimidines. The overall resistance frequency (30\%) observed in Florida was twice as high as that reported recently from strawberry fields in the Carolinas for a smaller population collected in 2011 (19). However, similar or higher resistance frequencies, varying from 25 to $55 \%$, were reported in strawberry fields in California and Germany and from European and Chilean vineyards $(13,14,28,36)$. The higher resistance frequency $(36 \%)$ observed in the 2011-12 season may be due to an increase in usage of fenhexamid following the severe gray mold epidemic that affected most strawberry fields in central Florida in February of that year (4) or perhaps just because more isolates were tested in 2012 compared with the other years.

The ability of the HydR $3^{+}$isolates, carrying mutations at codons 170, 210, and 412 of the $\operatorname{erg} 27$ gene, to cause a control failure of fenhexamid was established. This is the first report of a high level of resistance conferred by the G170R and A210G mutations. The G170R mutation was found at low frequency and is located in a domain of the $\operatorname{erg} 27$ protein only present in $B$. cinerea (1), whereas the A210G mutation was found at a higher frequency in Florida

Table 3. Mutations in the erg27 gene linked with resistance to fenhexamid in Botrytis cinerea from strawberry fields in Florida and sensitivity of HydR3and $\mathrm{HydR} 3^{+}$on detached fruit sprayed with fenhexamid

\begin{tabular}{|c|c|c|c|c|c|c|c|c|}
\hline \multicolumn{2}{|c|}{ Mutation in erg27 } & \multirow[b]{2}{*}{$\mathbf{R F}^{\mathbf{x}}$} & \multirow[b]{2}{*}{$n^{y}$} & \multirow[b]{2}{*}{ Isolates $^{\mathrm{Z}}$} & \multicolumn{2}{|c|}{ Incidence $^{t}$} & \multicolumn{2}{|c|}{ Sporulation $^{\mathrm{u}}$} \\
\hline Pheno, aav & Changew $^{w}$ & & & & 3 dpi & 7 dpi & 3 dpi & 7 dpi \\
\hline \multicolumn{9}{|l|}{ HydR3 } \\
\hline V192L & $G \mathrm{TT}$ to CTT & 25 & 1 & $12-327$ & 0.0 & 0.0 & _- & - \\
\hline N196T & $\mathrm{A} A \mathrm{~T}$ to $\mathrm{ACT}$ & $35-40$ & 2 & $13-53,13-69$ & 0.0 & 0.0 & - & - \\
\hline $\mathrm{I} 232 \mathrm{M}$ & $\mathrm{ATT}$ to ATG & $30-45$ & 2 & $12-38,13-393$ & 0.0 & 12.5 & - & + \\
\hline $\mathrm{P} 238 \mathrm{~S}$ & $C C \mathrm{~T}$ to $\mathbf{T C T}$ & 40 & 1 & 13-391 & 0.0 & 0.0 & - & - \\
\hline $\mathrm{P} 250 \mathrm{~S}$ & $C C C$ to $\mathbf{T C C}$ & $35-45$ & 3 & $13-53, \mathbf{1 3 - 6 9 ,} 13-67$ & 0.0 & 0.0 & - & - \\
\hline$\Delta \mathrm{P} 298$ & $\ldots$ & $20-40$ & 4 & $12-69, \mathbf{1 2 - 3 5 3}, \mathbf{1 3 - 5 3}, 13-69$ & 0.0 & 0.0 & - & _- \\
\hline L400F & TTA to TTC & $350-68$ & 6 & $\mathbf{1 1 - 5 8}, 12-35,12-36, \mathbf{1 2 - 4 8}$ & 0.0 & 0.0 & - & - \\
\hline A461S & $G \mathrm{CT}$ to $\mathbf{T C T}$ & $26-49$ & 13 & $\begin{array}{l}\mathbf{1 2 - 1 9}, 12-24,12-33,12-47, \mathbf{1 2 - 5 8}, 12-93,12-109,12-122, \\
12-124,12-148,12-320,12-331,12-340\end{array}$ & 0.0 & 0.0 & - & - \\
\hline \multicolumn{9}{|c|}{ 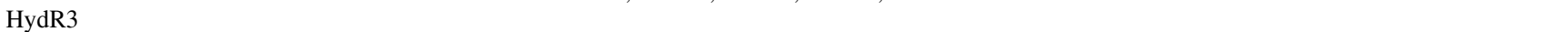 } \\
\hline G170R & $G \mathrm{GG}$ to $\mathbf{A G G}$ & $42-50$ & 2 & 13-222, 12-377 & 100.0 & 100.0 & +++ & +++ \\
\hline A210G & GGC to GGG & $41-58$ & 8 & $\begin{array}{l}\text { 12-362, 13-42, 13-138, 13-236, 13-238, 13-315, 13-331, } \\
13-377\end{array}$ & 100.0 & 100.0 & ++++ & ++++ \\
\hline F412I & $T$ TC to ATC & $326-2,200$ & 27 & $\begin{array}{l}\mathbf{1 2 - 3 2},-50,-78,-80,-82 \text { to }-84,-89,-91, \mathbf{- 1 2 3},-143,-154 \\
-165,-166,-191, \mathbf{- 3 3 0},-338,-341,-386,-388, \mathbf{- 4 1 2},-437 \\
-439,-458,-459,-460,-461\end{array}$ & 100.0 & 100.0 & ++++ & ++++ \\
\hline $\mathrm{F} 412 \mathrm{~V}$ & TTC to GTC & $159-386$ & 14 & $\begin{array}{l}\mathbf{1 1 - 0 6},-21,-25,-48,-108,-109,12-105,-129,-\mathbf{1 4 4},-152 \\
\mathbf{- 3 6 8},-415,-436,-454\end{array}$ & 100.0 & 100.0 & +++ & +++ \\
\hline $\mathrm{F} 412 \mathrm{~S}$ & $\begin{array}{l}\text { TTC to } \\
\text { TCC/TCT }\end{array}$ & $41-594$ & 87 & $\begin{array}{l}\text { 11-23, }-45,-59,-60,-61,-63,-73,-90,-107,-110,12-26, \\
-32,-39,-49,-51 \text { to } 54,-60,-61,-66,-67,-77,-81,-85 \\
-87,-88,-90,-92,-94,-96,-97,-107,-111,-114,-125 \\
-126,-131 \text { to } 136,-145,-146,-149 \text { to } 151,-153,-164 \\
-178,-181,-182,-316 \text { to }-319,-321,-326,-328,-332 \text { to } \\
-335,-342,-351 \text { to } 354,-371,-372,-382,-383,-387,-395 \text {, } \\
-403,-416,-427 \text { to }-432,-435,-446,-448,-455, \mathbf{1 3 - 2 4 0}\end{array}$ & 100.0 & 100.0 & +++ & +++ \\
\hline
\end{tabular}

\footnotetext{
${ }^{t}$ Gray mold incidence (\%) on blackberry fruit after 3 and 7 days of incubation at $22^{\circ} \mathrm{C}$ (days post inoculation [dpi]). Results are the mean of 16 replicate fruit across two experimental runs. Fruit were preventively sprayed with fenhexamid (Elevate) at $1.8 \mathrm{~g} /$ liter and inoculated $24 \mathrm{~h}$ later with $40 \mu \mathrm{l}$ of conidial suspension at $10^{6}$ conidia/ml.

"Sporulation was assessed visually in comparison with the untreated control;,,-+++++ , and ++++ indicate no sporulation, weak sporulation, strong sporulation, and similar to control, respectively.

${ }^{v}$ Phenotype and amino acid. HydR3 ${ }^{-}$and HydR $3^{+}$indicate isolates with moderate and high resistance, respectively, to fenhexamid in vitro.

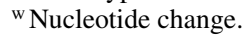

${ }^{\mathrm{x}}$ Resistance factor $(\mathrm{RF})$ range.

${ }^{\mathrm{y}}$ Number of isolates for each mutant group.

${ }^{\mathrm{z}}$ The first and the second numbers of each isolate indicate the year of isolation and isolate reference, respectively. Isolates in bold were used for fruit tests.
} 
and in isolates collected from different locations. The alanine at codon 210 is well conserved among species (1) and is located 10 amino acids downstream of the well-conserved NAGI domain. These two mutations were not screened for in a large number of isolates but the presence of two restriction sites, HpyAV and CVIK1, within or in the vicinity of the G170 and A210 codons, respectively, would allow the development of PCR-RFLP assays and facilitate future monitoring of these mutations. Interestingly, mutants carrying the A210G substitution grew faster and sporulated profusely compared with the other $\mathrm{HydR}^{+}$mutants (data not shown), which may denote a strong fitness.

The predominance of the F412S and the presence of the F412I and - V mutations in the Florida population is consistent with previous reports $(13,14,19)$. Recently, the F412V mutation was not detected among 214 isolates investigated in the Carolinas but another substitution (F412C) conferring a high level of resistance was described instead (19). A phenylalanine to valine mutation was reported at codon 427 in one isolate from grape in New York (34). Additional mutations associated with the HydR $3^{+}$phenotype (i.e., T63I [19] and N369D [13,14]) were described previously at low frequencies but were not found in Florida. Most HydR $3^{+}$isolates had RFs greater than 100; however, a few isolates, mainly those carrying the F412S mutation, had RFs between 41 and 80 , which is likely due to differences in natural inherent sensitivities among isolates, as suggested previously (14).

The mutation frequency in the erg27 gene was higher in the $\mathrm{HydR}^{-}$phenotype, conferring moderate resistance to fenhexamid in vitro. Seven mutations and one deletion were characterized among this phenotype. Interestingly, the mutation of the asparagine of the NAGI domain to threonine (N196T) did not affect the sensitivity of $B$. cinerea to fenhexamid, which suggests that the NAGI domain may play an active role in the protein activity $(1,14)$ but not in fenhexamid binding. The I232M mutation, located next to a valine that is well conserved among species, was found only in two mutants but only one of them was fully controlled by fenhexamid on detached fruit $7 \mathrm{dpi}$ and was able to germinate and grow on fenhexamid at $0.5 \mu \mathrm{g} / \mathrm{ml}$ in vitro. The P238 and P250 residues are located in a domain only proper to $B$. cinerea. Interestingly, the P238S mutation has been reported in both HydR3 $3^{-}$and HydR3 ${ }^{+}$ isolates by Esterio et al. (13) in Chilean vineyards but no indication of their ability to cause control failure was documented. However, the only P238S mutant found in Florida was a HydR3 ${ }^{-}$and was fully controlled by fenhexamid on detached fruit. The proline deletion at codon $298(\Delta \mathrm{P} 298)$ was also reported by Esterio et al. (13) in HydR3 $3^{-}$and HydR3 $3^{+}$isolates but was detected only in HydR3 ${ }^{-}$ isolates from Florida. The later were controlled on detached fruit sprayed with the RFR of fenhexamid. These dissimilarities are most likely due to the range of resistance factors and the growth stage used to characterize the isolates in vitro. Combining in vitro and in vivo tests would clearly distinguish the $\mathrm{HydR}^{+}$isolate solely capable of causing control failure from the HydR3 $3^{-}$isolates, regardless of the RF established from in vitro assays. The A461S mutation, described herein for the first time, was the most frequent among the HydR ${ }^{-}$isolates, whereas the $\mathrm{L} 400 \mathrm{~F}$ and $-\mathrm{S}$ mutations

Table 4. Efficacy of prochloraz and metconazole against multiple genotypes of Botrytis cinerea on detached fruit

\begin{tabular}{llrrrrr}
\hline & & \multicolumn{3}{c}{ Gray mold incidence $^{\mathbf{z}}$} \\
\cline { 3 - 4 } & & \multicolumn{2}{c}{ Prochloraz } & & \multicolumn{2}{c}{ Metconazole } \\
\cline { 3 - 4 } \cline { 6 - 7 } Isolate & Genotype & $\mathbf{5 ~ d p i}$ & $\mathbf{7 ~ d p i}$ & & $\mathbf{5 ~ d p i}$ & $\mathbf{7 ~ d p i}$ \\
\hline $08-97$ & Wild type & 0.0 & 25.0 & & 50.0 & 50.0 \\
$11-07$ & Wild type & 25.0 & 50.0 & & 0.0 & 70.0 \\
$12-176$ & Wild type & 0.0 & 0.0 & & 0.0 & 50.0 \\
$13-222$ & G170R & 25.0 & 50.0 & & 0.0 & 0.0 \\
$13-362$ & A210G & 0.0 & 0.0 & & 0.0 & 50.0 \\
$13-138$ & A210G & 0.0 & 0.0 & & 0.0 & 25.0 \\
$11-107$ & F412S & 25.0 & 50.0 & & 50.0 & 100.0 \\
$11-90$ & F412S & 0.0 & 25.0 & & 0.0 & 50.0 \\
$11-48$ & F412V & 0.0 & 0.0 & & 0.0 & 0.0 \\
$11-06$ & F412V & 0.0 & 25.0 & & 25.0 & 75.0 \\
$11-82$ & F412I & 25.0 & 50.0 & & 50.0 & 75.0 \\
$12-154$ & F412I & 0.0 & 25.0 & & 75.0 & 100.0 \\
\hline
\end{tabular}

${ }^{\mathrm{z}}$ Gray mold incidence on blackberry fruit after 5 and 7 days of incubation at $22^{\circ} \mathrm{C}$ (days post inoculation [dpi]). Results are the mean of 12 replicate fruit across two experimental runs. Fruit were preventively sprayed with prochloraz (Sportak) and metconazole (Quash) at 0.27 and $225 \mu \mathrm{g} / \mathrm{ml}$, respectively and inoculated $5 \mathrm{~h}$ later with $40 \mu \mathrm{l}$ of conidial suspension at $10^{6}$ conidia/ml.

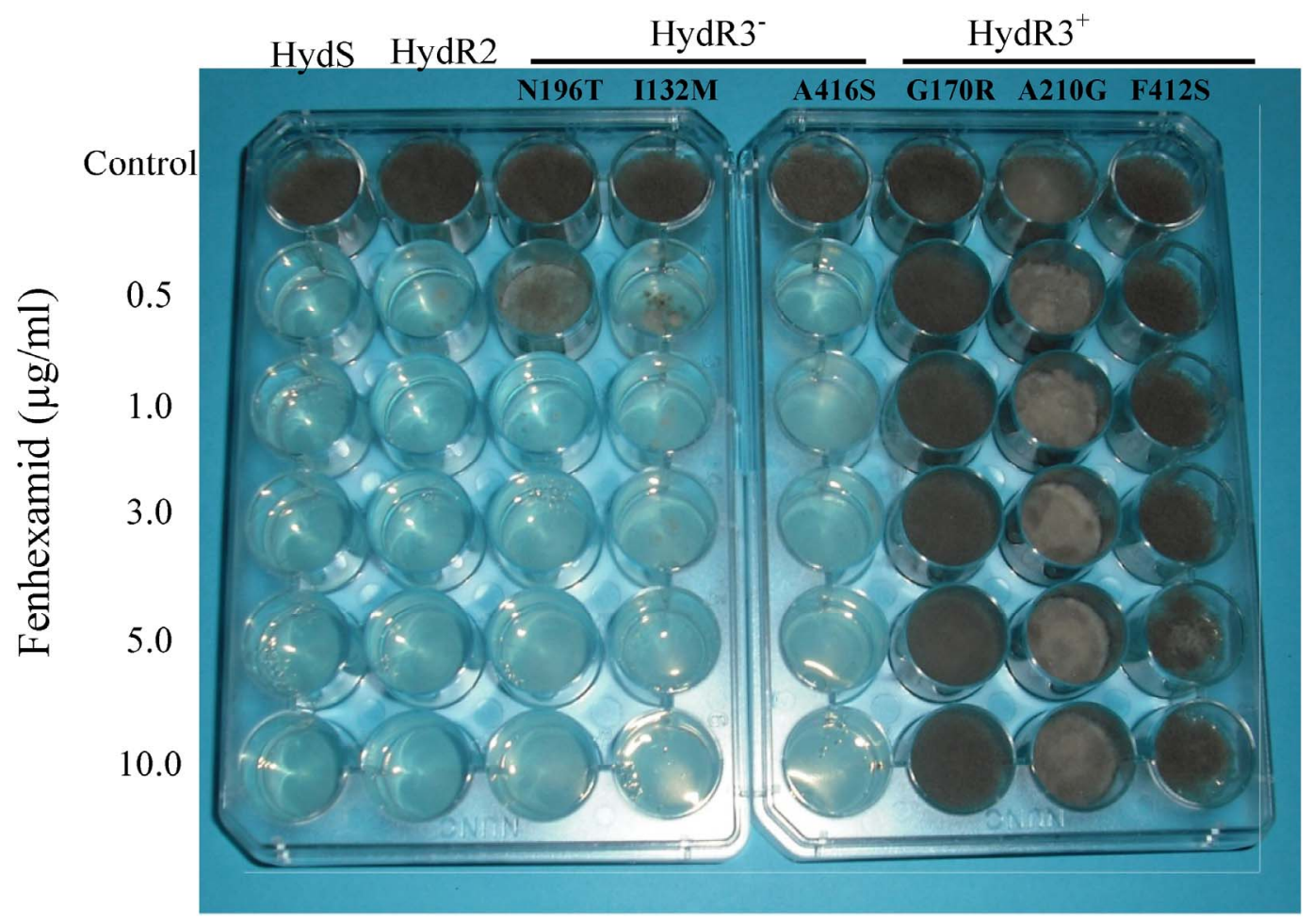

Fig. 2. Growth of Botrytis cinerea isolates from Hyd ${ }^{S}$ (08-97), HydR2 (12-176), HydR3- (12-53, 12-38, and 11-58), and HydR3+ (13-222, 13-138, and 11-107) phenotypes on potato dextrose agar amended with different concentrations of fenhexamid after 8 days of incubation at $22^{\circ} \mathrm{C}$. 
have been reported previously in HydR3 $3^{-}$isolates $(13,14)$. These mutations are located close to or within the C-terminal transmembrane domain and were suggested to play a role in fenhexamid binding but not in protein-protein interaction in the C-4 demethylation complex (11). The fact that none of the mutations detected in the HydR $3^{-}$isolates was found in the HydR $3^{+}$isolates in our study may suggest that the HydR $3^{-}$population is unlikely to develop resistance to fenhexamid quicker than the $\mathrm{Hyd}^{\mathrm{S}}$ or the HydR2. Symptoms of gray mold caused by HydR3 ${ }^{-}$isolates on untreated control fruit were visible only after 5 days of incubation and sporulation was significantly weaker, confirming previous reports on increased fitness cost and counter selection associated with the HydR3 ${ }^{-}$isolates $(13,14)$. However, the ability of the HydR2 phenotypes, which represented $25 \%$ of the Florida population, to detoxify fenhexamid and to develop resistance quicker than the $\mathrm{Hyd}^{\mathrm{S}}$ isolates requires future investigations.

Two mechanisms of action have been suggested for fenhexamid (i.e., a decrease in ergosterol amount or an increased accumulation of sterone intermediates; 10). A recent study has shed some light on the exact mechanism of action in relation to the different resistance phenotypes (11). In the presence of fenhexamid, a small decrease in ergosterol content and no sterone accumulation were apparent in $\mathrm{HydR}^{+}$isolates whereas, interestingly, large amounts of sterone derivatives and a significant decrease in ergosterol were detected in the $\mathrm{Hyd}^{\mathrm{S}}$ and HydR3- ${ }^{-}$isolates (11). Furthermore, the 3$\mathrm{KR}$ activity was reduced in HydR $3^{-}$isolates carrying the L400S and $-\mathrm{F}$ amino acid substitutions and the HydR $3^{+}$carrying the F412S, -V, and -I mutations by a factor of 1.5 to 5 compared with the $\mathrm{Hyd}^{\mathrm{S}}$ isolates but was not completely inhibited (11). However, fenhexamid inhibited the 3-KR enzyme 25 and 150 times more in the $\mathrm{Hyd}^{\mathrm{S}}$ isolates compared with $\mathrm{HydR}^{-}$and the HydR3 ${ }^{+}$, respectively, suggesting a decreased affinity of fenhexamid with the target site on the 3-KR enzyme of the HydR3 ${ }^{+}$isolates (11).

Although fenhexamid has been in use for over a decade in Florida, the overall resistance frequency $(30 \%)$ is lower than that of other fungicides registered afterward such as the SDHIs, the QoIs, and thiophanate-methyl $(2,4)$ but not the dicarboxamide iprodione (18), which was registered well before fenhexamid in Florida. Our study did not allow a clear conclusion on the effect of number of sprays on selection for resistant populations. Frequencies as high as 17 to $20 \%$ were observed in most locations where fenhexamid was applied once during the peak bloom period or twice early in the season, such as in the PC location in 2011. In a recent field study on grape in New York, the number of fenhexamid sprays per year affected control efficacy against gray mold but not the selection for resistant populations (34). Conducive weather conditions could also increase risks of widespread resistant populations as seen in 2012 in Florida, with about 50\% resistant isolates in some locations. The relatively slow development of fenhexamid-resistant populations could also be explained by the inability of isolates carrying mutations in the erg 27 gene to survive under unfavorable conditions $(8,9,38)$. Mertely et al. (29) reported that fenhexamid was most active against $B$. cinerea at anthesis and that a 7- to 14day delay would significantly reduce its efficacy. Spraying fenhexamid twice a season in strawberry fields when weather conditions are moderately conducive between early February and midMarch in rotation with other fungicides from different chemical groups would be a good strategy to extend the life of fenhexamid and delay the selection for additional resistant populations.

The widespread occurrence of multifungicide-resistant populations of $B$. cinerea warrants the development and registration of new effective fungicides. In an effort to explore other potential effective molecules that might be part of future gray mold management programs, we investigated the efficacy of other SBIs. The F412S isolates, the most frequent mutants, were particularly sensitive to all SBIs in vitro. Whether this constitutes an additional fitness cost requires future evaluation, including all genotypes to other botrycides. Prochloraz and metconazole applied at low rates were effective $5 \mathrm{dpi}$. Prochloraz and tebuconazole are among the SBIs that are registered to control gray mold, mostly on vegetable crops in countries other than the United States. These two fungicides were found to have either an independent effect or some additive effect with fenhexamid against $B$. cinerea (9). Other SBIs (i.e., the DMIs propiconazole and flusilazol and the amine fenpropimorph) were effective at $0.1 \mathrm{mg} / \mathrm{ml}$ against gray mold on cucumber in the greenhouse (27). In a 2010 field study on grape in New York, metconazole (Quash) was as affective as fenhexamid in reducing gray mold incidence and severity (7). The relatively low doses recommended for most DMIs have been suggested to be the reason for their limited field efficacy (24). In our study, prochloraz and metconazole were used at the lowest recommended rates and the efficacy could certainly be improved if higher rates are used. Future field studies are needed to evaluate the efficacy of these SBIs in strawberry commercial field before potential recommendation for gray mold control are made.

\section{Acknowledgments}

This research was supported by a United States Department of Agriculture NIFA fund under project number 2010-51181-21113. We thank S. M. Heath, A I. Zuniga, and R. Martin for their technical assistance.

\section{Literature Cited}

1. Albertini, C., and Leroux, P. 2004. A Botrytis cinerea putative 3-keto reductase gene (ERG27) that is homologous to the mammalian 17 beta-hydroxysteroid dehydrogenase type 7 gene (17 beta-HSD7). Eur. J. Plant Pathol 110:723-733

2. Amiri, A., Heath, S. M., and Peres, N. A. 2013. Phenotypic characterization of multifungicide resistance in Botrytis cinerea isolates from strawberry fields in Florida. Plant Dis. 97:393-401.

3. Amiri, A., Heath, S. M., and Peres, N. A. 2014. Resistance to fluopyram, fluxapyroxad, and penthiopyrad in Botrytis cinerea from strawberry. Plant Dis. 98:532-539.

4. Amiri, A., Peres, A. N., and Whidden, A. 2012. Perspective on resistance of Botrytis cinerea from strawberry to multiple fungicides in Florida. Berry Vegetable Times, University of Florida IFAS Extension. Special alert. http://strawberry.ifas.ufl.edu/BVT0312.pdf

5. Bardas, G. A., Veloukas, T., Koutiba, O., and Karaoglanidis, G. S. 2010. Multiple resistance of Botrytis cinerea from kiwifruit to SdhIs, QoIs and fungicides of other chemical groups. Pest Manage. Sci. 66:967-973.

6. Baroffio, C. A., Siegfried, W., and Hilber, U. W. 2003. Long-term monitoring for resistance of Botryotinia fuckeliana to anilinopyrimidine, phenylpyrrole, and hydroxyanilide fungicides in Switzerland. Plant Dis. 87:662-666.

7. Bay, I. S., Eynard, J. D., and Gubler, W. D. 2010. Fungicide programs for control of Botrytis bunch rot of grapes, 2010. Plant Dis. Manage. Rep. 5:SMF010.

8. Billard, A., Fillinger, S., Leroux, P., Lachaise, H., Beffa, R., and Debieu, D 2011. Strong evidence to the fungicide fenhexamid entails a fitness cost in Botrytis cinerea, as shown by comparisons of isogenic strains. Pest Manage. Sci. 68:684-691.

9. Billard, A., Fillinger, S., Leroux, P., Solignac, P., Lachaise, H., Beffa, R. and Debieu, D. 2011. Fenhexamid resistance in Botrytis pseudocinerea: Target modifications and fungicide detoxification. Pages 111-121 in: Modern Fungicides and Antifungal Compounds VI. Deutsche Phytomedizinische Gesellschaft, Braunschweig, Germany.

10. Debieu, D., Bach, J., Hugon, M., Malosse, C., and Leroux, P. 2001. The hydroxyanilide fenhexamid, a new sterol biosynthesis inhibitor fungicide efficient against the plant pathogenic fungus Botryotinia fuckeliana (Botrytis cinerea). Pest Manage. Sci. 57:1060-1067.

11. Debieu, D., Bach, J., Montesinos, E., Fillinger, S., and Leroux, P. 2012 Role of sterol 3-ketoreductase sensitivity in susceptibility to the fungicide fenhexamid in Botrytis cinerea and other phytopathogenic fungi. Pest Manage. Sci. 69:642-651.

12. Esterio, M., Auger, J., Ramos, C., and García, H. 2007. First report of fenhexamid resistant isolates of Botrytis cinerea on grapevine in Chile. Plant Dis. 91:768.

13. Esterio, M., Ramos, C., Walker, A. S., Fillinger, S., Leroux, P., and Auger, J. 2011. Phenotypic and genetic characterization of Chilean isolates of Botrytis cinerea with different levels of sensitivity to fenhexamid. Phytopathol. Mediterr. 50:414-420.

14. Fillinger, S., Leroux, P., Auclair, C., Barreau, C., Al Hajj, C., and Debieu, D. 2008. Genetic analysis of fenhexamid-resistant field isolates of the phy topathogenic fungus Botrytis cinerea. Antimicrob. Agents Chem. 52:39333940 .

15. Förster, H., Kanetis, L., and Adaskaveg, J. E. 2004. Spiral gradient dilution, a rapid method for determining growth responses and 50\% effective concentration values in fungus-fungicide interactions. Phytopathology 94:163170.

16. Fournier, N., Giraud, T., Albertini, C., and Brygoo, Y. 2005. Partition of the Botrytis cinerea complex in France using multiple gene genealogies. Mycologia 97:1251-1267. 
17. Fungicide Resistance Action Committee. FRAC Code List. http://www. frac.info

18. Grabke, A., Fernández-Ortuño, D., Amiri, A., Li, X., Peres, N. A., Smith, P., and Schnabel, G. 2014. Characterization of iprodione resistance in Botrytis cinerea from strawberry and blackberry. Phytopathology 104:396-402.

19. Grabke, A., Fernández-Ortuño, D., and Schnabel, G. 2012. Fenhexamid resistance in Botrytis cinerea from strawberry fields in the Carolinas is associated with four target gene mutations. Plant Dis. 97:271-276.

20. Hänssler, G., and Pontzen, R. 1999. Effects of fenhexamid on the development of Botrytis cinerea. Pflanzenschutz Nachr. Bayer (Ger. Ed.) 52:158176.

21. Köller, W. 1992. Antifungal agents with target sites in sterol function and biosynthesis. Pages 119-206 in: Target Sites of Fungicide Action. W. Köller, ed. CRC Press, Boca Raton, FL.

22. Legard, D. E., MacKenzie, S. J., Mertely, J. C., Chandler, C. K., and Peres, N. A. 2005. Development of a reduced use fungicide program for control of Botrytis fruit rot on annual winter strawberry. Plant Dis. 89:1353-1358.

23. Leroch, M., Kretschmer M., and Hahn, M. 2011. Fungicide resistance phenotypes of Botrytis cinerea isolates from commercial vineyards in south west Germany. J. Phytopathol. 159:63-65.

24. Leroux, L. 2007. Chemical control of Botrytis and it resistance to chemical fungicides, Pages 195-222 in: Botrytis: Biology, Pathology and Control. Y. Elad et al., eds. Springer, Dordrecht, the Netherlands.

25. Leroux, P., Chapeland, F., Desbrosses, D., and Gredt, M. 1999. Patterns of cross-resistance to fungicides in Botryotinia fuckeliana (Botrytis cinerea) isolates from French vineyards. Crop Prot. 18:687-697.

26. Leroux, P., Fritz, R., Debieu, D., Albertini, C., Lanen, C., Bach, J., Gredt, M., and Chapeland, F. 2002. Mechanisms of resistance to fungicides in field strains of Botrytis cinerea. Pest Manage. Sci. 58:876-888.

27. Markoglou, A. N., and Ziogas, B. N. 2002. SBI-fungicides: fungicidal effectiveness and resistance in Botrytis cinerea. Phytopathol. Mediterr. 41:120-130.

28. Mercier, J., Kong, M., Cook, J. 2010. Fungicide resistance among Botrytis cinerea isolates from California strawberry fields. Plant Health Progress. Online publication. doi:10.1097/PHP-210-0806-01-RS

29. Mertely, J. C., MacKenzie, S. J., and Legard, D. E. 2002. Timing of fungicide applications for Botrytis cinerea based on development stage of strawberry flowers and fruit. Plant Dis. 86:1019-1024.

30. Moorman, G. W., Walker, A-S., and May, S. 2012. First report of fenhexamid-resistant Botrytis cinerea causing gray mold Heuchera in North America greenhouse. Plant Dis. 96:147.

31. Myresiotis, C. K., Karaoglanidis, G. S., and Tzavella-Klonari, K. 2007. Resistance of Botrytis cinerea isolates from vegetable crops to anilinopyrimidine, phenylpyrrole, hydroxyanilide, benzimidazole, and dicarboximide fungicides. Plant Dis. 91:407-413.

32. Rosslenbroich, H. J., and Stuebler, D. 2000. Botrytis cinerea-history of chemical control and novel fungicides for its management. Crop Prot. 19:557-561.

33. Saito, S., Cadle-Davidson, L., and Wilcox, W. F. 2011. Practical resistance to fenhexamid in Botrytis cinerea isolates from grapevines in New York. (Abstr.) Phytopathology 101:S158.

34. Saito, S., Cadle-Davidson, L., and Wilcox, W. F. 2013. Selection, fitness, and control of grape isolates of Botrytis cinerea variably resistant to fenhexamid. Plant Dis. 98:233-240.

35. Santos, B. M., Peres, N. A., Price, J. F., Chandler, C. K., Whitaker, V. W., Stall, W. M., Olson, Smith S. A., and Simone E. H. 2011. Strawberry production in Florida. Pages 271-282 in: Vegetable Production Handbook for Florida. University of Florida-IFAS Extension, Gainesville.

36. Weber, R. W. S. 2011. Resistance of Botrytis cinerea to multiple fungicides in Northern German small-fruit production. Plant Dis. 95:1263-1269.

37. Williamson, B., Tudzynsk, B., Tudzynski, P., and van Kan, J. A. L. 2007. Botrytis cinerea: the cause of grey mould disease. Mol. Plant Pathol. 8:561580 .

38. Ziogas, B. N., Markoglou, A. N., and Malandrakis, A. A. 2003. Studies on the inherent resistance risk to fenhexamid in Botrytis cinerea. Eur. J. Plant Pathol. 109:311-317. 